Please do not remove this page

RMIT

UNIVERSITY

\title{
Proof stress measurement of die-cast magnesium alloys
}

ANG, Hua Qian; Abbott, Trevor; Zhu, Suming; Gu, Chengfan; Easton, Mark

https://researchrepository.rmit.edu.au/esploro/outputs/9921858760601341/filesAndLinks?institution=61RMIT_INST\&index=null

ANG, H. Q., Abbott, T., Zhu, S., Gu, C., \& Easton, M. (2016). Proof stress measurement of die-cast magnesium alloys. Materials and Design, 112(ISS), 402-409. https://doi.org/10.1016/j.matdes.2016.09.088 Document Version: Accepted Manuscript

Published Version: https://doi.org/10.1016/j.matdes.2016.09.088

Repository homepage: https://researchrepository.rmit.edu.au

CC BY-NC-ND V4.0

(C) 2016 Elsevier Ltd. All rights reserved.

Downloaded On 2023/04/26 19:57:22 +1000

Please do not remove this page 


\title{
Proof stress measurement of die-cast magnesium alloys
}

\author{
Hua Qian Anga ${ }^{\mathrm{a}}$, Trevor B. Abbott ${ }^{\mathrm{a}, \mathrm{b}}$, Suming Zhu ${ }^{\mathrm{a}}$, Chengfan $\mathrm{Gu}^{\mathrm{a}}$, Mark A. Easton ${ }^{\mathrm{a}, *}$ \\ ${ }^{a}$ School of Engineering, RMIT University, Bundoora, Victoria 3083, Australia \\ ${ }^{b}$ Magontec Limited, Sydney, New South Wales 2000, Australia
}

\begin{abstract}
Magnesium and its alloys exhibit not only elastic and plastic behaviour but also anelastic behaviour upon loading. The presence of anelastic strain poses a challenge to the measurement of proof stress using conventional methods. As such, the proof stress measurement methods specified by American Society for Testing and Materials (ASTM) and International Standards Organization (ISO) are reviewed and applied to three common die-cast magnesium alloys including AE44, AM60 and AZ91. The methods in the standards give inconsistent results due largely to the inherent anelastic behaviour of these alloys. The widely used $0.2 \%$ offset strain method tends to underestimate proof stress whilst the $0.2 \%$ permanent plastic strain method requires repeated loading and unloading. In view of the fact that the non-equivalence between the offset strain and the residual plastic strain for magnesium alloys is a key obstacle to the accurate proof stress measurement, a conversion chart is constructed to enable the determination of the appropriate offset strain for a desired residual plastic strain for a range of magnesium alloys. It is shown that employing a higher offset strain than $0.2 \%$ has an advantage in reproducibility of proof stress measurement.
\end{abstract}

Keywords: Magnesium alloys; High-pressure die-casting; Measurement; Proof stress; Anelasticity

* Corresponding author. Tel: +61 399256278

E-mail address: mark.easton@rmit.edu.au 


\section{Introduction}

Tensile testing is one of the most commonly used methods to assess material properties. The key tensile properties include: yield strength (YS) or proof stress (PS), elastic modulus, tensile strength and elongation to failure. The tensile strength and elongation to failure can be readily determined. Yield strength is used for materials with clear yielding phenomena such as plain carbon steel. For austenitic steels and non-ferrous metals, such as aluminium and magnesium, there is no sharply defined yielding of the material, and hence, proof stress is used as a substitute for yield stress [1]. Studies of high-pressure die-cast magnesium alloys have shown that non-uniform yielding is even more pronounced due to the bimodal grain microstructure [2], where yielding develops first in the softer core [3] consisting of predominantly large externally solidified grains (ESG) while the outer layer of the casting, which consists of mostly fine $\alpha$-magnesium grains [4], remains elastic (it should be noted, however, that die casting technology is continually improving and these variations are arguably less significant in modern machines).

Proof stress is determined by the stress corresponding to the intersection of the stress-strain curve and a line parallel to the linear elastic part of the curve offset by a definite amount of permanent plastic strain [5]; the permanent strain allowed is an arbitrary choice, ranging from $0.1 \%$ for ferrous to $0.5 \%$ for some non-ferrous materials $[6,7]$. For convenience, a permanent plastic strain of $0.2 \%$ has been adopted for most metallic materials. The permanent plastic strain can only be determined from a monotonic stress-strain curve if the non-permanent strain can be determined and subtracted. With linear elastic strain this is straightforward, but with non-linear reversible strain (anelastic strain), it is only possible if this anelastic behaviour is fully characterised.

The anelasticity of magnesium alloys manifests itself in a variety of different ways. Under cyclic stress, anelastic behaviour takes the form of a stress-strain hysteresis loop, as identified in magnesium and magnesium-zinc alloys [8], AZ91 (Mg-9Al-0.6Zn) [9], AM60 (Mg-6Al-0.3Mn) and AE44 (Mg-4Al-4RE) [10]. The monotonic stress-strain curve of magnesium has a very small linear elastic portion, making elastic modulus determination difficult [11]. The nominal elastic modulus $(E)$ value for magnesium and its alloys is commonly taken as $45 \mathrm{GPa}$ through ultrasonic methods [12], although this value has been shown to vary with solute content, volume fraction of precipitates and porosity [13]. The deviation from elastic behaviour occurs at stresses as low as $20 \mathrm{MPa}$, due to the activation of basal slip (microyielding) [14]. The variable apparent modulus leads immediately to ambiguities in proof stress determination.

Scientific exchange rests on agreed standards for the measurement of properties. In the case of tensile testing standards (for example ASTM E8M-09 [15] and ISO 6892-1 [16]), four methods are presented for proof stress determination applicable to magnesium as shown in Fig. 1. Detailed descriptions of methods $1 \& 2$ can be found in ASTM E8M-09 [15] while methods $3 \& 4$ in ISO 6892-1 [16].

Inconsistencies between and within these methods frustrate attempts to compare alloy properties. AE44, AM60 and AZ91 are commercially available magnesium die-casting alloys for automotive applications, and therefore, they are the center of attention in this study. In this paper, these alloys are tested according to tensile testing standards and the magnitudes of inconsistencies are determined. More practical proof stress determination methods for magnesium die-casting alloys are discussed. 


\section{Materials and Experimental Details}

\subsection{Materials}

Magnesium alloys AE44, AM60 and AZ91, and aluminium alloy A380 were high-pressure diecast (HPDC) in a 250 ton cold chamber machine. More details about the casting parameters can be found elsewhere [17]. The chemical compositions in wt.\% of the three magnesium alloys were analysed using inductively coupled plasma atomic emission spectroscopy (ICP-AES) by Spectrometer Services and are listed in Table 1. The study was carried out using cast-to-size cylindrical cross section, dog-bone shaped tensile specimens of gauge diameter $5.6 \mathrm{~mm}$ and uniform length of $36 \mathrm{~mm}$.

\subsection{Mechanical Testing}

Both monotonic (Methods 1 and 2) and cyclic tension loading-unloading tests (Methods 3 and 4) were performed on an Instron 5569 Universal Testing Machine (UTS) with a $50 \mathrm{kN}$ load cell at room temperature using a crosshead speed of $5 \mathrm{~mm} / \mathrm{min}$. Two to three repeats were performed per alloy composition and test condition. For Method 3, the loading-unloading tests were strain-controlled, unloading at predetermined strains to zero stress. For Method 4, the loading-unloading tests were stress-controlled, unloading at predetermined stress to $10 \%$ of the stress obtained. A $25 \mathrm{~mm}$ gauge length extensometer was attached to the specimen and digital output files of the flow curves were converted to stress-strain curves.

\section{Results}

\subsection{Proof Stress Measurement: Method 1}

The engineering stress-strain curves of AE44, AM60, AZ91 and A380 are shown in Fig. 2a. It is seen that the linear elastic behaviour of the three magnesium alloys applies only at low stress levels ( $\angle 40 \mathrm{MPa}$ ), where the elastic modulus of magnesium alloys, $E=45 \mathrm{GPa}$ [12] is measured. The aluminium alloy A380, on the other hand, has a more clearly defined linear elastic region (up to $>100 \mathrm{MPa}$ ) where the elastic modulus value of $E=70 \mathrm{GPa}$ can be easily measured.

The relatively small linear elastic region of magnesium alloys makes elastic modulus determination difficult; elastic modulus decreases with increasing stress levels used for modulus determination. As shown in Fig. 2b, the elastic modulus is $45 \mathrm{GPa}$ when it is estimated from the low stress region at $20 \mathrm{MPa}$; the elastic modulus decreases to $38 \mathrm{GPa}$ when it is estimated from higher stress region at $60 \mathrm{MPa}$ for AE44. Offsetting a lower elastic modulus to $0.2 \%$ permanent plastic strain would tilt the offset line forward, leading to higher measured proof stress value (as illustrated in Fig. 2b).

The proof stress values, measured by method 1 through offsetting a constant elastic modulus of $45 \mathrm{GPa}$ to $0.2 \%$ strain are $123 \pm 5.5 \mathrm{MPa}, 117 \pm 3.7 \mathrm{MPa}$ and $154 \pm 6.0 \mathrm{MPa}$, respectively for cast AE44, AM60 and AZ91, whereas the proof stress value for A380 is $185 \pm 0.7 \mathrm{MPa}$ through offsetting an elastic modulus of $70 \mathrm{GPa}$. 


\subsection{Proof Stress Measurement: Method 2}

Since the linear elastic region of the stress-strain curve in magnesium is not clearly defined, Method 2, extension-under-load (EUL), can be employed. According to the ASTM standard [15], materials with low yield strengths of less than $550 \mathrm{MPa}$, an appropriate value of total extension is $0.005 \mathrm{~mm} / \mathrm{mm}$ or $0.5 \%$ of the gauge length. The proof stress values obtained from Method 2 are $127 \pm 2.8 \mathrm{MPa}, 122 \pm 2.4 \mathrm{MPa}$, and 148 $\pm 4.6 \mathrm{MPa}$ respectively, for cast AE44, AM60 and AZ91 and $187 \pm 1.4 \mathrm{MPa}$ for A380 as shown in Fig. 3.

\subsection{Proof Stress Measurement: Method 3}

Based on Method 3, a line should be drawn across hysteresis loop unloaded to $0.2 \%$ permanent plastic strain. The point at which this line intersects the curve gives the $0.2 \%$ proof stress. However, it is often difficult to pre-determine the applied strain and stress that would unload to $0.2 \%$ plastic strain due to the uneven hysteresis loops. Hence, each test was unloaded and reloaded six times as indicated by the hysteresis loops formed as shown in Fig. 4 for AE44. Similar hysteresis loops were observed for AM60 and AZ91. A series of secant elastic moduli, $E_{\text {sec}}$, indicated by dashed line, are also defined in Fig. 4.

Here, the hysteresis loops still did not unload to $0.2 \%$ plastic strain after several loadingunloading cycles. Hence, $0.2 \%$ proof stress is measured by a $E_{\mathrm{sec}}$ (as indicated by dotted line in Fig. 4 ), interpolated from elastic moduli drawn across hysteresis loops unloading to plastic strains before and after $0.2 \%$. The average interpolated $E_{\text {sec }}$ at $0.2 \%$ strain in Method 3 for AE44, AM60 and AZ91 are $23.9 \pm 0.4 \mathrm{GPa}, 24.3 \pm 0.7 \mathrm{GPa}$ and $26.9 \pm 0.6 \mathrm{GPa}$ respectively. The proof stress values measured by Method 3 are summarised in Table 2.

The cyclic stress-strain curve of A380 is also shown in Fig. 5 for comparison. It is worth noting that the loops are small and the elastic modulus remains unchanged ( $E=70 \mathrm{GPa}$ ) with increasing strain. The measured anelastic strains (defined by loop width) are close to zero. The proof stress of A380 measured by method 3 is $187 \pm 0.7 \mathrm{MPa}$, which is similar to the proof stress values measured by Methods 1 (185 MPa) and 2 (187 MPa).

Generally, $E_{\mathrm{sec}}$ decreases with increasing permanent plastic strain when the hysteresis loops become larger until a point where the loops are fully developed. At this point, there will be little change in $E_{\text {sec. }}$ This is similar for all the magnesium alloys tested (Fig. 6a). Published work from Mann et al. [8] and Cáceres et al. [9] have been reanalysed and included for comparison. The two HPDC AZ91 2 mm-thick and 6 mm-thick alloys by Cáceres et al. [9] appear to have a higher $E_{\text {sec }}$ than the HPDC alloys in this study at $0.2 \%$ permanent plastic strain, an indication of smaller hysteresis loop. Stronger materials, i.e. HPDC and aged sand cast, also show a smaller decrease in $E_{\text {sec }}$ compared with the lower strength sand cast alloys.

Fig. $6 \mathrm{~b}$ shows the anelastic strain as a function of permanent plastic strain. It is clear that the anelastic strain is approximately $0.25 \%$ at $0.2 \%$ permanent plastic strain for all the alloys tested in this study. The two HPDC AZ91 $2 \mathrm{~mm}$-thick and $6 \mathrm{~mm}$-thick alloys by Cáceres et al. [9] have a slightly lower anelastic strain $(0.2 \%)$ than the HPDC alloys tested in this study at $0.2 \%$ plastic strain. It is also interesting to note that most sand cast samples, which have larger grain sizes, show lower anelastic strain $(0.1-0.15 \%)$ at $0.2 \%$ plastic strain. Overall, pure magnesium metal shows higher anelastic strain than the alloys for given casting condition. 


\subsection{Proof Stress Measurement: Method 4}

Based on Method 4, the stress is reduced to about $10 \%$ of the unloading stress when the presumed proof stress is reached to obtain an alternative elastic modulus, $E_{\text {alt }}$ for proof stress determination. But, it is impossible to pre-identify when the proof stress is exceeded unless loadingunloading tests are conducted in advance. Here, based on previously conducted monotonic tests (tensile curves shown in Fig. 2a, AE44, AM60 and AZ91 were unloaded at $123 \mathrm{MPa}, 117 \mathrm{MPa}$ and $154 \mathrm{MPa}$ respectively (average proof stress values obtained from Method 1). A380 has constant $E_{\text {sec }}$ with increasing strain, and therefore was not subjected to this test. The cyclic stress-strain curve for AE44 and $E_{\text {alt }}$ following Method 4 are shown in Fig. 7. According to Method $4, E_{\text {alt }}$ must be tangential to the stress-strain curve and the point where this line crosses the abscissa is taken as the corrected origin. Hence, in this case, $E_{\text {alt }}$ is offset from negative strain rather than at the origin (Fig. 7). The average $E_{\text {alt }}$ used in Method 4 for AE44, AM60 and AZ91 are 33.3 $\pm 0.9,32.1 \pm 1.4$, and $33.2 \pm 1.1 \mathrm{GPa}$ respectively.

One conundrum of Method 4 is to determine where to unload. Unloading at different stress levels yields different alternative elastic moduli, resulting in a variation in proof stress values as illustrated in Fig. 8, ranging from 148 to $158 \mathrm{MPa}$.

\section{Discussion}

\subsection{Applicability of the Current Standardized Methods to Die-Cast Magnesium Alloys}

The proof stress of magnesium alloys reported in literature [18-29] is often defined by Method 1 ( $0.2 \%$ offset) due to its simplicity as compared to Methods 3 and 4 . Method 2 is often used to determine the acceptance or rejection of materials whose stress-strain characteristics are well-known from previous tests [30], and hence, is less commonly used in published work. To investigate the inconsistencies in these standardized methods, Figs. 2a and 3 (monotonic stress-strain curves) are overlaid onto Figs. 4 and 7 (cyclic stress-strain curves for Methods 3 and 4 respectively) as shown in Fig. 9 for cast AE44, AM60 and AZ91. The following comments can be made from the comparison of the standardized methods:

(a) The proof stress values measured by Methods 1 and 2 do not leave a $0.2 \%$ permanent plastic strain in die-cast magnesium alloys, in fact it is less than $0.1 \%$ plastic strain upon the removal of anelastic deformation, $\varepsilon_{\text {aee }}$. Hence, Methods 1 and 2 significantly underestimate the $0.2 \%$ proof stress of magnesium alloys.

(b) Method 3 more accurately measures the proof stress of magnesium alloys, but it is almost impossible to pre-determine the stress or strain amplitudes that impart $0.2 \%$ permanent plastic deformation upon unloading. Hence, repeated loading-unloading tests have to be conducted, and this becomes time consuming and impractical.

(c) Method 4 itself is inconsistent in that the proof stress value is dependent upon the unloading stress level.

\subsection{Appropriate Offset Strain for Magnesium Alloys}

Methods 1-4 provide different proof stress values for the same magnesium alloy tested. Clearly, proof stress measurement methods specified in ASTM and ISO standard analysis procedures need to be re-evaluated for magnesium and its alloys due to the existence of anelastic strain and for 
simplicity. Since the monotonic curves are similar to the cyclic stress-strain curves with the absence of hysteresis loops (Fig. 9), for die-cast AE44, AM60 and AZ91, it was found that the 0.2\% proof stress values determined by Method 3 could be measured directly from monotonic stress-strain curves with an appropriate offset strain value. This would save considerable amount of time and effort without performing cyclic loading-unloading tests. An appropriate offset strain value should always consider the anelasticity at $0.2 \%$ permanent plastic strain .

It is shown in Fig. 10 that the appropriate offset strain for magnesium alloys to achieve a $0.2 \%$ permanent strain proof stress can range from $0.3-0.45 \%$ depending on the alloy and casting conditions. The HPDC alloys in this study requires a higher offset strain of $0.45 \%$ as compared to the HPDC alloys used by Cáceres et al. [9]. This could also be due to grain size effect as those HPDC alloys may have had a greater fraction of large presolidified grains formed in the shot sleeve.

Similarly, sand cast samples, with larger grain sizes, show a lower offset strain $(\approx 0.3 \%)$ compared to HPDC samples. A small grain size has been reported to result in a greater number of fine $\{10 \overline{1} 2\}$ twins which are less stable and more prone to revert upon unloading, magnifying the anelastic strain $[8,9]$. In extension, as anelastic strain increases, so does the offset strain at given permanent plastic strain.

It is also interesting to note that magnesium-zinc alloys appear to have a lower anelastic strain than pure magnesium for a given casting condition; anelastic effect decreases with increasing $\mathrm{Zn}$ content (Fig. 6b). This is because presence of solutes (i.e. Zn [8]) is able to enhance the dislocation activity in the prismatic slip system, and hence, twinning becomes progressively less necessary in the magnesium alloys [31]. Since anelasticity is known to be caused by the reversible movement of twin boundaries, it is reasonable to believe that decreasing twinning reduces the anelastic strain, and therefore, a slightly lower offset strain is required for the magnesium alloys than pure magnesium. The three die-cast magnesium alloys AE44, AM60 and AZ91 tested in this study also have a different $\mathrm{Al}$ concentration, but $\mathrm{Al}$ solutes appear to have little effects on the anelastic strain as compared to $\mathrm{Zn}$. This can be understood by noting that $\mathrm{Zn}$ develops short range order [32] while $\mathrm{Al}$ forms random solid solutions [33]. Twinning in magnesium is shuffling dominated [34], and therefore, it should be more sensitive to the presence of order [35] than existence of a random solid solution. It is worth noting that the microstructure of AE44 consists of Al-RE intermetallic phases (i.e. $\mathrm{Al}_{11} \mathrm{RE}_{3}$ and $\mathrm{Al}_{2} \mathrm{RE}$ [36]), while that of $\mathrm{AM} 60$ and $\mathrm{AZ91}$ consist of $\mathrm{Mg}_{17} \mathrm{Al}_{12}$ phase [37]. The difference in intermetallic phases do not seem to affect the anelastic behaviour of the investigated alloys in the present study, these factors are subject to ongoing investigation.

It should also be pointed out that Fig. 10 is only applicable for tensile testing. Depending on manufacturing processes, some magnesium alloys are known to have a larger anelastic strain in compression than tension [8] due to an increased activity of $\{10 \overline{1} 2\}$ twinning [38], and hence, a larger offset strain might be required for compression testing under such condition. However, HPDC samples commonly have isotropic material behaviour [39], therefore, the increase in offset strain should be negligible for HPDC magnesium alloys.

As for twinning-free aluminium alloy A380, due to its negligible anelastic effect, the $0.2 \%$ offset strain is able to achieve a $0.2 \%$ permanent strain for proof stress measurement.

\subsection{Effects of Higher Offset Strain on Measurement Consistency}

The purpose of yield or proof stress is to indicate the stress, above which significant plastic deformation occurs. Fig. 11 shows an example of a stress-strain curve (in this case AM60) with 0.2 
and $0.5 \%$ offset strains marked. From the inset in Fig. 11, point A ( $0.5 \%$ offset) gives a more diagnostic property value than point B $(0.2 \%$ offset $)$. The $0.2 \%$ offset value lies on the steep part of the curve well before significant plastic deformation has occurred and is of no special significance.

In section 3.1, it was noted that differences in the stress level chosen for modulus determination could shift the apparent modulus from $45 \mathrm{GPa}$ to $38 \mathrm{GPa}$. Fig. 11 illustrates that the effect of modulus determination errors is much greater in the $0.2 \%$ offset proof stress compared to $0.5 \%$ offset proof stress. In the former case the result shifts by $8 \mathrm{MPa}$ while in the later the shift is only $2 \mathrm{MPa}$. Section 3.1 also illustrated that sample to sample variations at $0.2 \%$ offset where also higher, being almost an order of magnitude higher than for aluminium.

The proof stress values measured by $0.5 \%$ offset method for die-cast AE44, AM60 and AZ91 in this study are summarized in Table 2. Regardless of testing methods, AZ91 is consistently having the highest proof stress as compared to AE44 and AM60. AZ91 is well-known to be a stronger but less ductile alloy due to the presence of high volume fraction of coarse and brittle $\beta-\mathrm{Mg}_{17} \mathrm{Al}_{12}$ phase in the microstructure [40]. It is evident that the values measured by $0.5 \%$ offset method correlate well with those measured by method 3, and they are far larger than the proof stress values from the $0.2 \%$ offset rule (method 1). Room temperature tensile stress-strain data of high-pressure die-cast magnesium and aluminium alloys from independent studies in the literature have been reanalysed to compare the proof stress obtained by the $0.2 \%$ and $0.5 \%$ offsets (Table 3). For exact chemical compositions, refer to original studies. By using a higher offset strain, the proof stress of both magnesium and aluminium alloys can increase up to $20 \%$. Overall, higher offset method provides a smaller range of proof stress values, and hence, a more consistent measure for magnesium alloys.

However, caution should be taken when considering $0.5 \%$ offset method to die-cast magnesium alloys as it has also been shown in Fig. 6 that the anelastic strain is sensitive to factors such as grain size and solutes. It should be noted that some of the sand cast magnesium alloys have a lower anelastic strain, and the higher offset strain of $0.5 \%$ might overestimate the proof stress.

\section{Conclusions}

The applicability of the standardized ISO and ASTM proof stress determination methods to magnesium die-casting alloys has been investigated. The following conclusions are drawn from this study:

(1) Standardised proof stress determination methods provide inconsistent $0.2 \%$ permanent strain proof stress, with a variation of more than $20 \%$, due largely to the inherent anelastic behaviour of magnesium alloys.

(2) These methods either significantly underestimate the proof stress of magnesium alloys or they are too complex to be considered for routine application.

(3) A conversion chart has been constructed to provide a more accurate determination of $0.2 \%$ permanent plastic strain with an appropriate offset strain for a range of magnesium alloys. The appropriate offset strain is shown to vary from $0.3-0.45 \%$ depending on the casting conditions.

(4) A more pragmatic approach of using a higher offset strain and its effects are discussed. The high offset strain provides a smaller range of proof stress values as compared to the $0.2 \%$ offset strain, and hence, a more consistent measure. 


\section{Acknowledgements}

This work was supported by the Australian Research Council [Grant number LP130100828]. The authors would like to thank Dr. Carlos Cáceres from the University of Queensland for his very helpful comments on the manuscript.

\section{References}

[1] Rollason EC. Metallurgy for engineers. London: Edward Arnold; 1939.

[2] Yang KV, Cáceres CH, Easton MA. A microplasticity-based definition of the skin in $\mathrm{HPDC} \mathrm{Mg-}$ Al alloys. Mater Sci Eng A 2013; 580: 355-61.

[3] Yang KV, Cáceres CH, Nagasekhar AV, Easton MA. The skin effect and the yielding behavior of cold chamber high pressure die cast Mg-Al alloys. Mater Sci Eng A 2012; 542: 49-55.

[4] Weiler JP, Wood JT, Klassen RJ, Bermortel R, Wang G. The effect of grain size on the flow stress determined from spherical microindentation of die-cast magnesium AM60B alloy. J Mater Sci 2005; 40(22): 5999-6005.

[5] Beaumont RA. Metallurgy for aircraft engineers, inspectors and engineering students. London: Pitman; 1946.

[6] Hill FT. The materials of aircraft construction. London: Pitman \& Sons; 1942.

[7] Dieter GE. Mechanical metallurgy. 3rd ed. New York: McGraw-Hill; 1988.

[8] Mann GE, Sumitomo T, Cáceres CH, Griffiths JR. Reversible plastic strain during cyclic loading-unloading of $\mathrm{Mg}$ and $\mathrm{Mg}-\mathrm{Zn}$ alloys. Mater Sci Eng A 2007; 456(1):138-46.

[9] Cáceres CH, Sumitomo T, Veidt M. Pseudoelastic behaviour of cast magnesium AZ91 alloy under cyclic loading-unloading. Acta Mater 2003; 51(20): 6211-8.

[10] Lu Z, Blackmore P. Cyclic stress-Strain behaviour of AM60B and AE44 cast magnesium alloys and its impact on LCF characterisation and fatigue analysis. SAE Int J Materials and Manufacturing 2014; 7: 446-53.

[11] Carbonneau Y, Sanschagrin A, Renaud J, Tremblay R. On the development of a new approach for the determination of yield strength in Mg-based alloys. Light Metal Age 1998; 56(9-10): 503.

[12] Avedesian M, Baker H, editors. ASM Specialty Handbook: Magnesium and magnesium Alloys. Ohio: ASM International; 1999.

[13] Sumitomo T, Cáceres $\mathrm{CH}$, Veidt $\mathrm{M}$. The elastic modulus of cast $\mathrm{Mg}-\mathrm{Al}-\mathrm{Zn}$ alloys. J Light Metals 2002; 2(1): 49-56.

[14] Zhou A, Basu S, Barsoum M. Kinking nonlinear elasticity, damping and microyielding of hexagonal close-packed metals. Acta Mater 2008; 56(1): 60-7.

[15] ASTM Standard E8M-09 standard test methods for tension testing of metallic materials in annual book of ASTM standards, ASTM. West Conshohocken PA: American Society for Testing and Materials; 2009.

[16] ISO 6892-1 metallic materials tensile testing-part 1: method of test at room temperature. International Standards Organisation; 2009.

[17] Yang KV, Easton MA, and Cáceres $\mathrm{CH}$. The development of the skin in HPDC Mg-Al alloys. Mater Sci Eng A 2013; 580:191-5.

[18] Leng Z, Pan HJ, Niu ZY, Guo CH, Zhang Q, Chang YP, et al. Mechanical behavior, deformation and damage mechanisms of $\mathrm{Mg}-\mathrm{RY}-\mathrm{Zn}$ alloy under high strain rate. Mater Sci Eng A 2016; 651:336-40.

[19] Forsmark JH, Dowling Z, Gibson K, Mueller C, Godlewski L, Zindel J, et al. An investigation of the effects of cast skin on the mechanical properties of an AM60 die-cast magnesium alloy. SAE Int J Materials and Manufacturing 2015; 8: 714-21. 
[20] Okayasu M, Takeuchi S, Matsushita M, Tada N, Yamasaki M, Kawamura Y. Mechanical properties and failure characteristics of cast and extruded $\mathrm{Mg}_{97} \mathrm{Y}_{2} \mathrm{Zn}_{1}$ alloys with LPSO phase. Mater Sci Eng A 2016; 652: 14-29.

[21] Fintová S, Kunz L. Fatigue properties of magnesium alloy AZ91 processed by severe plastic deformation. J Mechanical Behavior of Biomedical Materials 2015; 42: 219-28.

[22] Jiang MG, Yan H, Chen R. Microstructure, texture and mechanical properties in an as-cast AZ61 Mg alloy during multi-directional impact forging and subsequent heat treatment. Mater Des 2015; 87: 891-900.

[23] Du YZ, Qian XG, Zheng MY, Wang DB, Wu K, Golovin IS. Effect of microalloying with Ca on the microstructure and mechanical properties of $\mathrm{Mg}-6$ mass\% $\mathrm{Zn}$ alloys. Mater Des 2016; 98:285-93.

[24] Wang HY, Zhang EB, Nan XL, Zhang L, Guan ZP, Jiang QC. A comparison of microstructure and mechanical properties of $\mathrm{Mg}-9 \mathrm{Al}-1 \mathrm{Zn}$ sheets rolled from as-cast, cast-rolling and asextruded alloys. Mater Des 2016; 89:167-72.

[25] Shabadi R, Ambat R, Dwarakadasa ES. AZ91C magnesium alloy modified by Cd. Mater Des 2014; 53: 445-51.

[26] Zhang L, Zhang JH, Leng Z, Liu SJ, Yang Q, Wu RZ, et al. Microstructure and mechanical properties of high-performance Mg-Y-Er-Zn extruded alloy. Mater Des 2014; 54: 256-63.

[27] She J, Pan FS, Guo W, Tang AT, Gao ZY, Luo SQ, et al. Effect of high Mn content on development of ultra-fine grain extruded magnesium alloy. Mater Des 2016; 90: 7-12.

[28] Jiang Y, Chen Y, Gao JJ. Comparative study regarding the effect of Al, Zn, and Gd on the microstructure and mechanical properties of Mg alloy Mg-Sn-Li. Mater Des 2016; 105: 34-40.

[29] Yang Q, Bu FQ, Meng FZ, Qiu X, Zhang, DP, Zheng T, et al. The improved effects by the combinative addition of lanthanum and samarium on the microstructures and the tensile properties of high-pressure die-cast Mg-4Al-based alloy. Mater Sci Eng A 2015; 628: 319-26.

[30] Davis JR, editor. Tensile testing. 2nd ed. Ohio: ASM international; 2004.

[31] Akhtar A and Teghtsoonian E. Solid solution strengthening of magnesium single crystals-II the effect of solute on the ease of prismatic slip. Acta Metall 1969; 17(11): 1351-6.

[32] Cáceres $\mathrm{CH}$ and Blake $\mathrm{AH}$. The strength of concentrated $\mathrm{Mg}-\mathrm{Zn}$ solid solutions. Physica Status Solidi (a) 2002; 194(1): 147-58.

[33] Cáceres $\mathrm{CH}$ and Rovera DM. Solid solution strengthening in concentrated $\mathrm{Mg}-\mathrm{Al}$ alloys. J Light Metals 2001; 1(3): 151-6.

[34] Li B, Kadiri HE, Zhang XY, Mathaudhu SN, Ma Q. Structural origin of reversible twinning, non-schmid effect, incoherent twin boundaries and texture of hexagonal close-packed metals. In: Mathaudhu SN, Sillekens WH, Neelameggham NR, Hort N, editors. Magnesium Technology 2012. London: John Wiley \& Sons; 2012. p. 105-10.

[35] Cahn JW. Thermodynamic and structural changes in deformation twinning of alloys. Acta Metall 1977; 25(9): 1021-6.

[36] Zhu SM, Easton MA, Abbott TB, Gibson MA, Nie JF. The influence of individual rare earth elements ( $\mathrm{La}, \mathrm{Ce}$, or $\mathrm{Nd}$ ) on creep resistance of die-cast magnesium alloy AE44. Adv Eng Mater 2016; 18(6): 932-7.

[37] Rettberg LH, Jordon JB, Horstemeyer MF, Jones JW. Low-cycle fatigue behavior of die-cast Mg alloys AZ91 and AM60. Metall Mater Trans A 2012; 43(7): 2260-74.

[38] Agnew SR, Duygulu Ö. Plastic anisotropy and the role of non-basal slip in magnesium alloy AZ31B. Int J of Plasticity 2005; 21(6):1161-93.

[39] Easton M, Song WQ, and Abbott T. A comparison of the deformation of magnesium alloys with aluminium and steel in tension, bending and buckling. Mater Des 2006; 27(10): 935-46.

[40] Boby A, Srinivasan A, Pillai UTS, Pai BC. Mechanical characterization and corrosion behavior of newly designed Sn and Y added AZ91 alloy. Mater Des 2015; 88: 871-9. 
[41] Zhang JH, Zhang ML, Meng J, Wu RZ, Tang DX. Microstructures and mechanical properties of heat-resistant high-pressure die-cast $\mathrm{Mg}-4 \mathrm{Al}-\mathrm{xLa}-0.3 \mathrm{Mn}(\mathrm{x}=1,2,4,6)$ alloys. Mater Sci Eng A 2010; 527(10): 2527-37.

[42] Zhu SM, Abbott TB, Gibson MA, Nie JF, Easton MA. Age hardening in die-cast Mg-Al-RE alloys due to minor Mn additions. Mater Sci Eng A 2016; 656: 34-8.

[43] Zhang JH, Leng Z, Zhang ML, Meng J, Wu RZ. Effect of Ce on microstructure, mechanical properties and corrosion behavior of high-pressure die-cast $\mathrm{Mg}-4 \mathrm{Al}$-based alloy. $\mathrm{J}$ Alloys Compd 2011; 509(3): 1069-78.

[44] Zhang JH, Zhang DP, Tian Z, Wang J, Liu K, Lu HY, et al. Microstructures, tensile properties and corrosion behavior of die-cast $\mathrm{Mg}$-4Al-based alloys containing La and/or Ce. Mater Sci Eng A 2008; 489(1): 113-9.

[45] Zhang JH, Yu P, Liu K, Fang DQ, Tang DX, Meng J. Effect of substituting cerium-rich mischmetal with lanthanum on microstructure and mechanical properties of die-cast $\mathrm{Mg}-\mathrm{Al}-\mathrm{RE}$ alloys. Mater Des 2009; 30(7): 2372-8.

[46] Zhang JH, Liu SJ, Leng Z, Liu XH, Niu ZY, Zhang ML, et al. Structure stability and mechanical properties of high-pressure die-cast $\mathrm{Mg}-\mathrm{Al}-\mathrm{La}-\mathrm{Y}$-based alloy. Mater Sci Eng A 2012; 531: 70-5.

[47] Gu GY, Lin ST, Xia Y, Zhou Q. Experimental study on influence of section thickness on mechanical behavior of die-cast AM60 magnesium alloy. Mater Des 2012; 38: 124-32

[48] Qi MF, Kang YL, Yang Y, Zhu GM, Liao WN. Comparison of microstructure and mechanical properties of AZ91D alloy formed by rheomolding and high-pressure die casting. J Materials Engineering and Performance 2015; 24(10): 3826-34.

[49] Yang Q, Guan K, Bu FQ, Zhang YQ, Qiu X, Zheng T, et al. Microstructures and tensile properties of a high-strength die-cast $\mathrm{Mg}-4 \mathrm{Al}-2 \mathrm{RE}-2 \mathrm{Ca}-0.3 \mathrm{Mn}$ alloy. Materials Characterization 2016; 113:180-8.

[50] Zhu SM, Easton MA, Abbott TB, Nie JF, Dargusch MS, Hort N, et al. Evaluation of magnesium die-casting alloys for elevated temperature applications: microstructure, tensile properties, and creep resistance. Metall Mater Trans A 2015; 46(8): 1-12.

[51] Chia TL, Easton MA, Zhu SM, Gibson MA, Birbilis N, Nie JF. The effect of alloy composition on the microstructure and tensile properties of binary Mg-rare earth alloys. Intermetallics 2009; 17(7): 481-90.

[52] Hébert G, Dubé D, Tremblay R. Tensile and fatigue behaviour of thin-walled cast A383.0 components. Mater Sci Eng A 2012; 552: 89-96.

[53] Hu ZQ, Wan L, Wu SS, Wu H, Liu XQ. Microstructure and mechanical properties of high strength die-casting Al-Mg-Si-Mn alloy. Mater Des 2013; 46: 451-6.

[54] Fan Z, Fang X, Ji S. Microstructure and mechanical properties of rheo-diecast (RDC) aluminium alloys. Mater Sci Eng A 2005; 412(1): 298-306. 
Table 1 Chemical compositions (wt.\%) determined by ICP-AES for the studied die-cast magnesium alloys

\begin{tabular}{cccccc}
\hline Alloy & Al & RE $($ Ce+La $)$ & Zn & Mn & Mg \\
\hline AE44 & 3.97 & 3.76 & $<0.01$ & 0.18 & Bal. \\
AM60 & 6.26 & $<0.01$ & 0.1 & 0.29 & Bal. \\
AZ91 & 8.88 & $<0.01$ & 0.74 & 0.19 & Bal. \\
\hline
\end{tabular}


Table 2 Proof stress values measured by Methods $1-4$ and the $0.5 \%$ offset method

\begin{tabular}{cccccc}
\hline \multirow{2}{*}{ Alloy } & \multicolumn{5}{c}{ Proof Stress (MPa) } \\
\cline { 2 - 6 } & Method 1 & Method 2 & Method 3 & Method 4 & 0.5\% Offset Method \\
\hline AE44 & $123 \pm 5.5$ & $127 \pm 2.8$ & $155 \pm 0.7$ & $148 \pm 1.4$ & $155 \pm 1.7$ \\
AM60 & $117 \pm 3.7$ & $122 \pm 2.4$ & $143 \pm 0.5$ & $136 \pm 1.0$ & $142 \pm 2.1$ \\
AZ91 & $154 \pm 6.0$ & $148 \pm 4.6$ & $185 \pm 2.8$ & $175 \pm 0.7$ & $181 \pm 4.2$ \\
A380 & $185 \pm 0.7$ & $187 \pm 1.4$ & $187 \pm 0.7$ & - & - \\
\hline
\end{tabular}


Table 3 Comparison of proof stress obtained by $0.2 \%$ and $0.5 \%$ offsets for HPDC magnesium and aluminium alloys reported in literature

\begin{tabular}{|c|c|c|c|}
\hline \multirow[b]{2}{*}{ Alloy } & \multicolumn{2}{|c|}{ Proof Stress (MPa) } & \multirow[b]{2}{*}{ Ref. } \\
\hline & $\begin{array}{l}\text { 0.2\% } \\
\text { offset }\end{array}$ & $\begin{array}{l}\text { 0.5\% } \\
\text { offset }\end{array}$ & \\
\hline \multicolumn{4}{|c|}{ Mg alloys } \\
\hline AM40 & $108^{*}-120$ & $127^{*}-133$ & \multirow{5}{*}{ [41] } \\
\hline $\mathrm{Mg}-4 \mathrm{Al}-1 \mathrm{La}$ & $110^{*}-133$ & $129^{*}-138$ & \\
\hline Mg-4Al-2La & $113^{*}-140$ & $137^{*}-148$ & \\
\hline $\mathrm{Mg}-4 \mathrm{Al}-4 \mathrm{La}$ & $128^{*}-155$ & $152^{*}-162$ & \\
\hline Mg-4Al-6La & 171 & 178 & \\
\hline $\mathrm{Mg}-4 \mathrm{Al}-3 \mathrm{La}$ & 123 & 148 & [42] \\
\hline $\mathrm{Mg}-4 \mathrm{Al}-1 \mathrm{Ce}$ & $129^{*}-146$ & $151^{*}-152$ & \multirow{4}{*}{ [43] } \\
\hline $\mathrm{Mg}-4 \mathrm{Al}-2 \mathrm{Ce}$ & 148 & 153 & \\
\hline $\mathrm{Mg}-4 \mathrm{Al}-4 \mathrm{Ce}$ & 157 & 162 & \\
\hline $\mathrm{Mg}-4 \mathrm{Al}-6 \mathrm{Ce}$ & 161 & 168 & \\
\hline $\mathrm{Mg}-4 \mathrm{Al}-4(\mathrm{Ce} / \mathrm{La})$ & $132 *-160$ & $161^{*}-170$ & [44] \\
\hline $\begin{array}{c}\text { AE44 (RE=Ce-rich } \\
\text { mischmetal) }\end{array}$ & $127^{*}-140$ & $149^{*}-154^{*}$ & [45] \\
\hline AM30 & 116 & 123 & [46] \\
\hline AM60 & $125-127^{*}$ & $144-148^{*}$ & [47] \\
\hline AZ91D & $150-154^{*}$ & $179^{*}-185$ & [48] \\
\hline AEX422 & 204 & 210 & [49] \\
\hline AE42 & 122 & 145 & \multirow{8}{*}{ [50] } \\
\hline AJ62 & 126 & 142 & \\
\hline AS31 & 127 & 145 & \\
\hline AXJ530 & 188 & 205 & \\
\hline AM-HP2+ & 175 & 173 & \\
\hline MRI 153A & 164 & 179 & \\
\hline MRI 153M & 162 & 174 & \\
\hline MRI 230D & 179 & 188 & \\
\hline $\mathrm{Mg}-3.44 \mathrm{La}$ & 135 & 172 & \multirow{6}{*}{ [51] } \\
\hline $\mathrm{Mg}-2.87 \mathrm{Ce}$ & 135 & 153 & \\
\hline $\mathrm{Mg}-3.53 \mathrm{Nd}$ & 129 & 135 & \\
\hline $\mathrm{Mg}-0.47 \mathrm{Nd}$ & 85 & 100 & \\
\hline $\mathrm{Mg}-0.51 \mathrm{La}$ & 80 & 98 & \\
\hline $\mathrm{Mg}-0.53 \mathrm{Ce}$ & 80 & 96 & \\
\hline \multicolumn{4}{|c|}{ Al alloys } \\
\hline A380 & 185 & 223 & This work \\
\hline A383 & $150-165$ & - & {$[52,53]$} \\
\hline A357 & $143-150$ & - & [54] \\
\hline AlMg5.5Si2Mn & 183 & - & [53] \\
\hline
\end{tabular}

${ }^{*}$ Unpublished data 

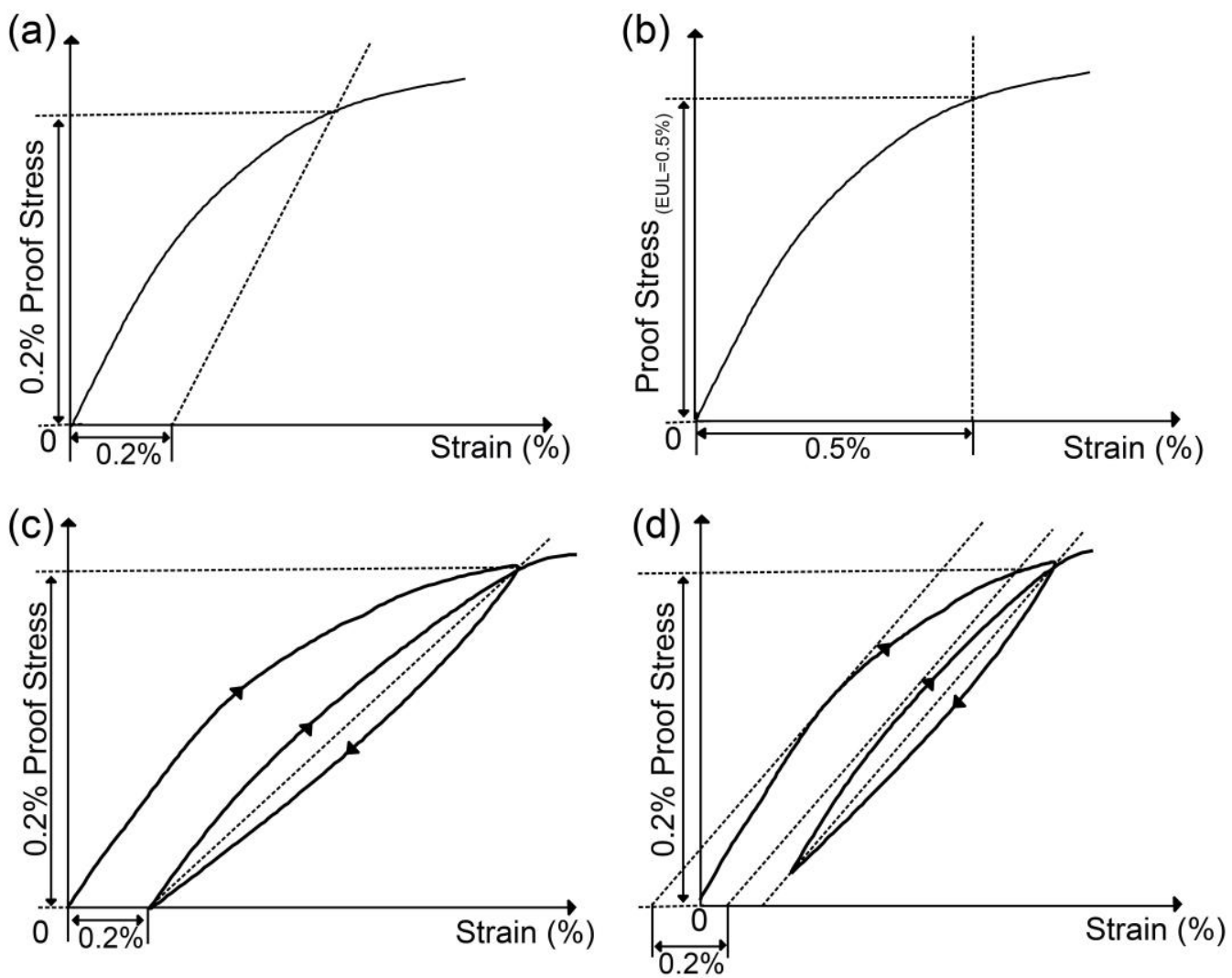

Fig. 1. Proof stress measurement methods: (a) Method 1, (b) Method 2 as specified in ASTM E8M09 [15] and (c) Method 3 and (d) Method 4 as stated in ISO 6892-1 [16]. 

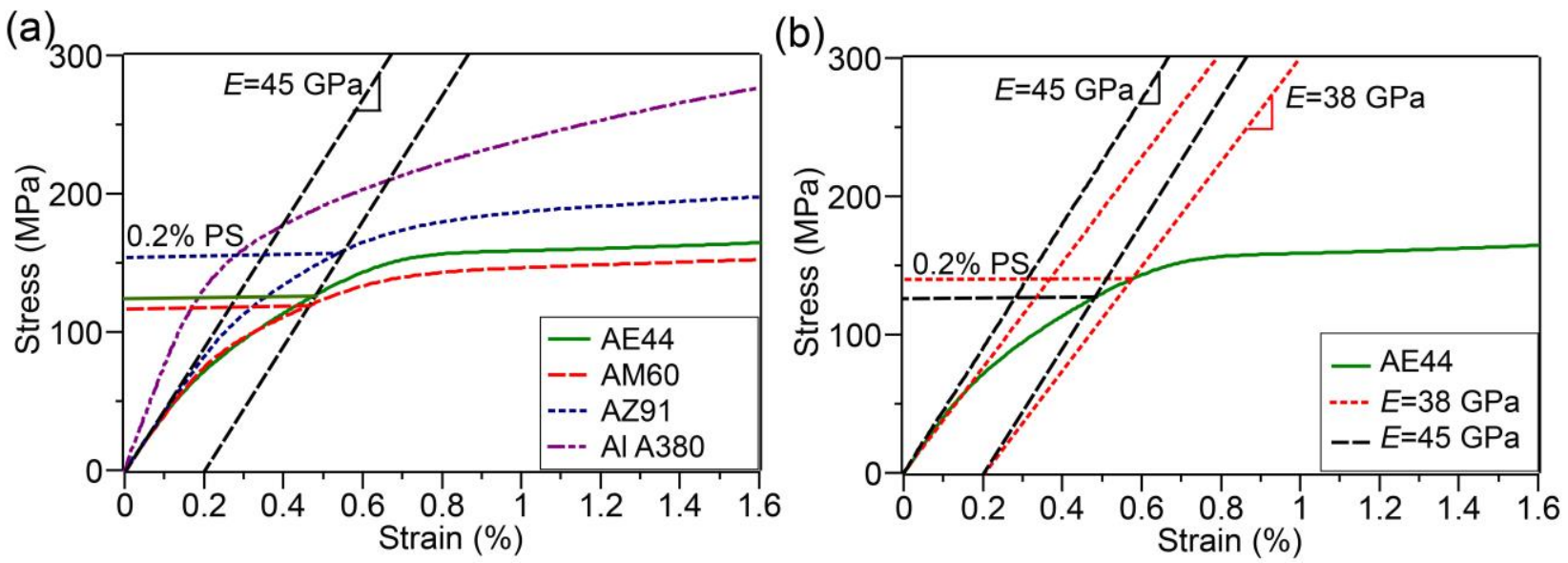

Fig. 2. Proof stress values measurement by Method 1 for die-cast AE44, AM60 and AZ91 alloys, indicated as $0.2 \%$ PS in (a) with $E=45 \mathrm{GPa}$ determined at low stresses (<40MPa).The aluminium alloy A380 is also shown for comparison. It is to be noted that the proof stress measured by Method 1 varies with $E$, which decreases from $45 \mathrm{GPa}$ to $38 \mathrm{GPa}$ with increasing stress from $>40 \mathrm{MPa}$ to $\sim 60$ $\mathrm{MPa}$, shown for AE44 in (b). 


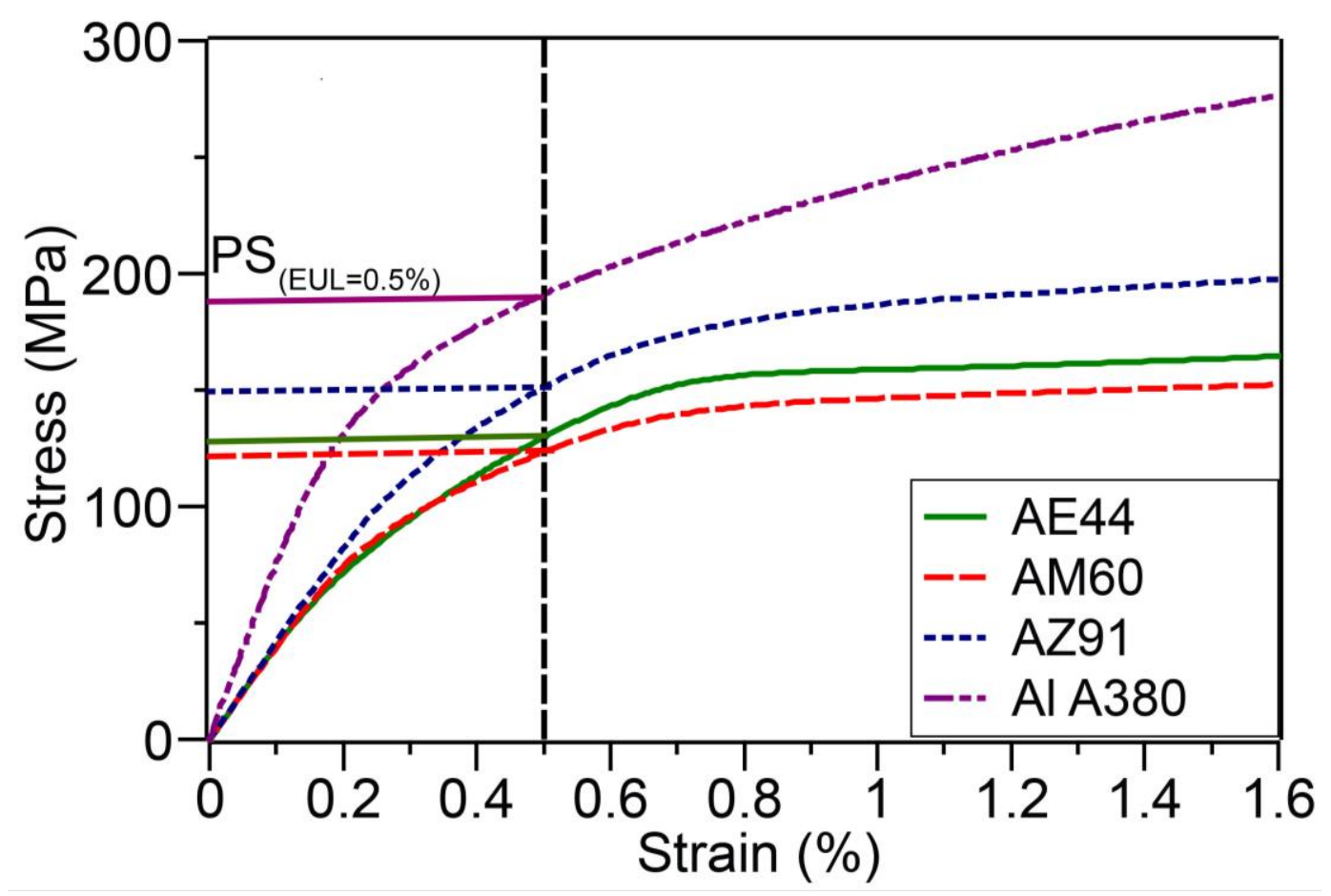

Fig.3. Tensile curves of die-cast AE44, AM60, AZ91 and A380 showing respectively proof stress values measured by method 2 . 


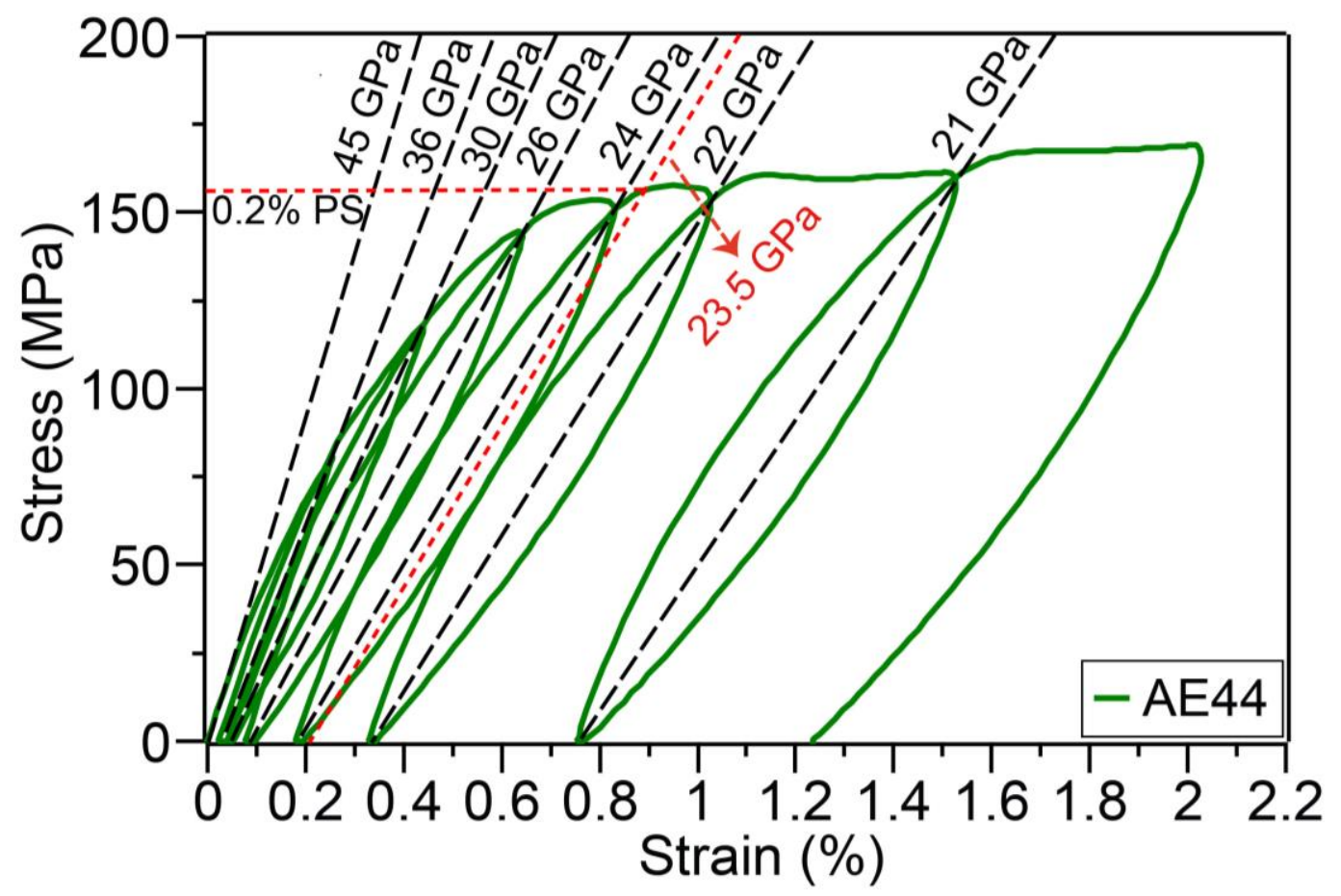

Fig. 4. Cyclic stress-strain curve of AE44 showing proof stress measured by Method 3, by employing a secant elastic modulus, $E_{\mathrm{sec}}$ of $23.5 \mathrm{GPa}$. 


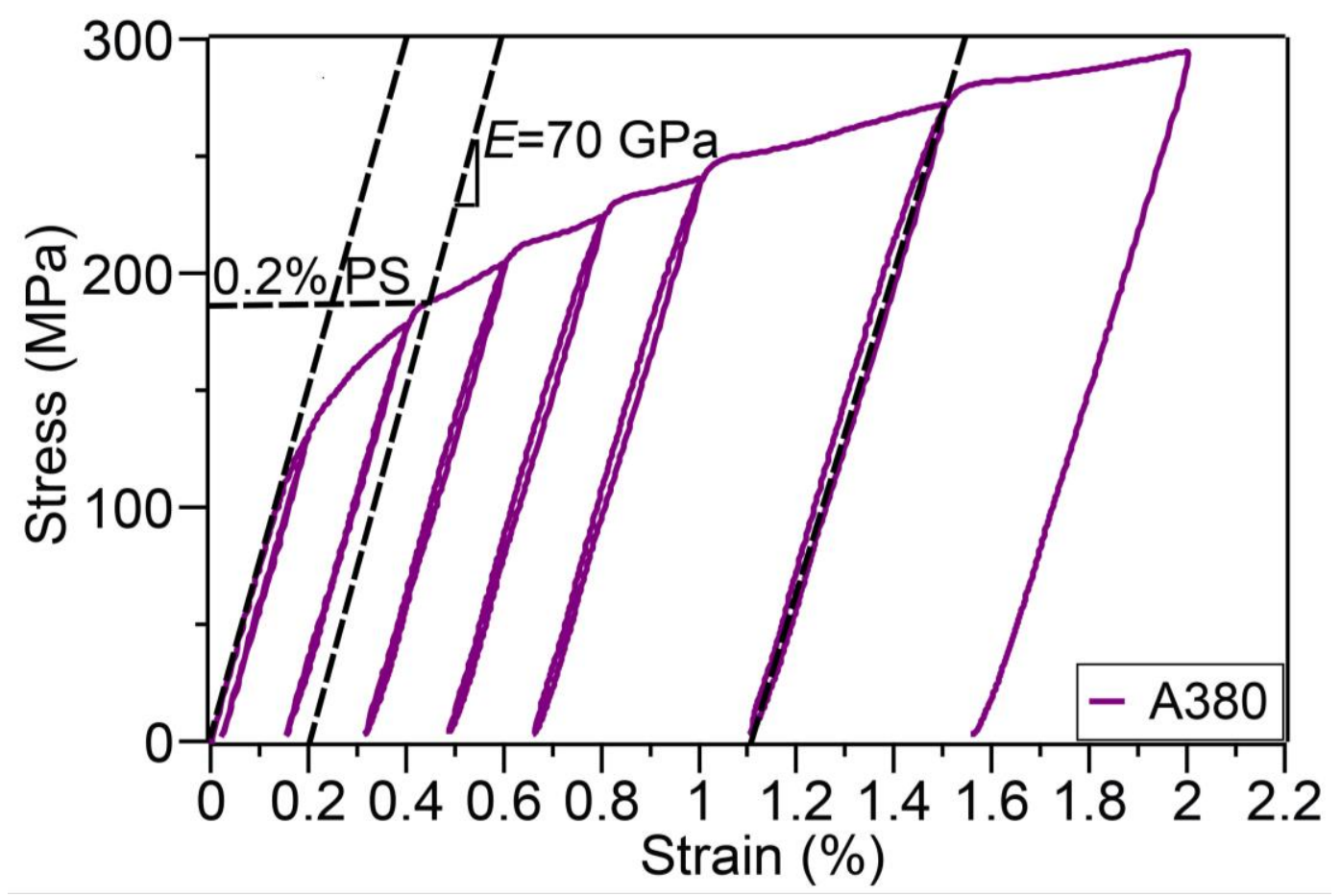

Fig. 5. Cyclic stress-strain curve of A380 showing proof stress measurement by Method 3. 
(a)

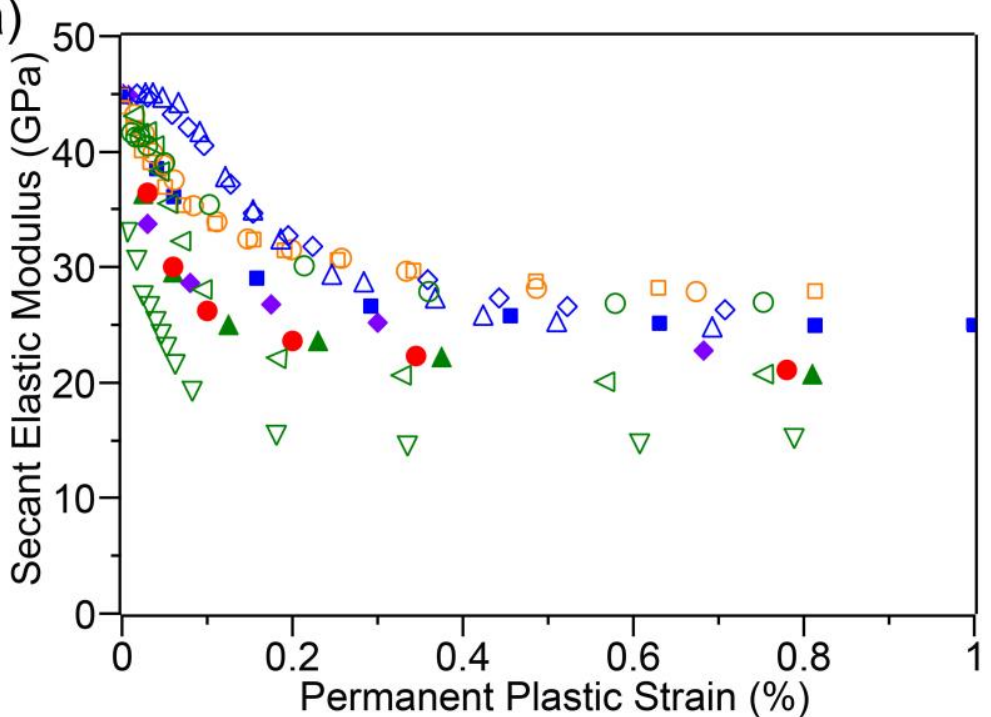

(b)

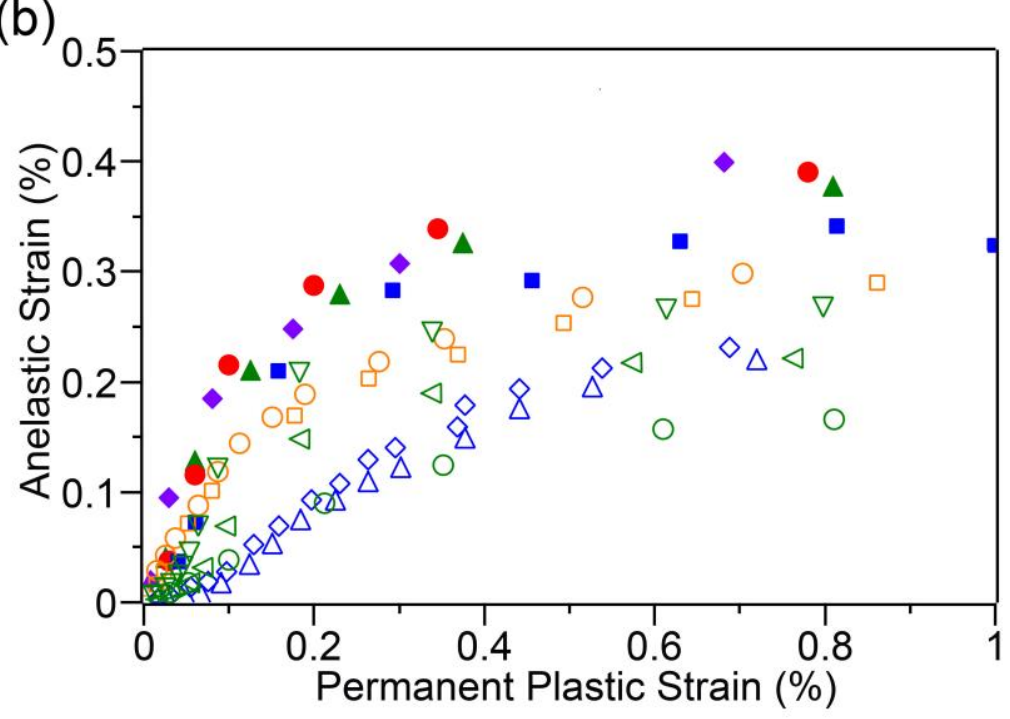

HPDC, present study grain size $=8 \mu \mathrm{m}$

$\triangle \mathrm{AM} 60$

AZ91

AE44-F

AE44-T5

Cáceres et al. 2003

$\square$ HPDC AZ91,2 mm thick HPDC AZ91,6 $\mathrm{mm}$ thick $\triangle$ Sand Cast AZ91-T4 Sand Cast AZ91-T5 Mann et al. 2007 $\nabla$ Sand Cast Pure Mg $\triangleleft$ Sand Cast Mg- $1 \% \mathrm{Zn}$ $\circ$ Sand Cast Mg- $6 \% \mathrm{Zn}$

Fig. 6. (a) Secant elastic modulus, $E_{\mathrm{sec}}(\mathrm{GPa})$ and (b) anelastic strain $(\%)$ as a function of tensile permanent plastic strain (\%). Data taken from published work by Mann et al. [8] and Cáceres et al. [9] are included for comparison. For experimental details, refer to original papers. 


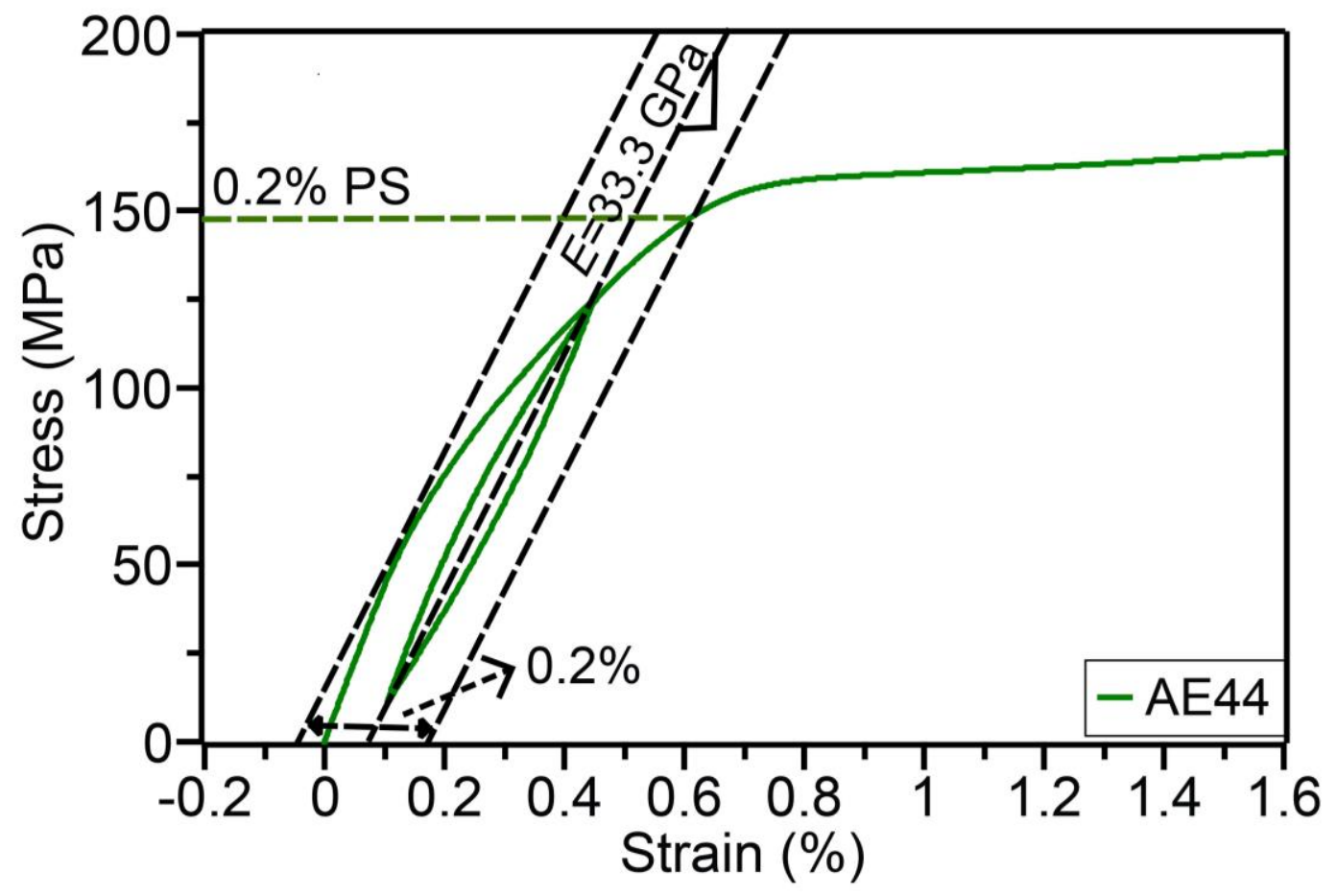

Fig.7. Proof stress measurement by Method 4 for AE44 where the alternative elastic modulus, $E_{\text {alt }}$ is $33.3 \mathrm{GPa}$. 


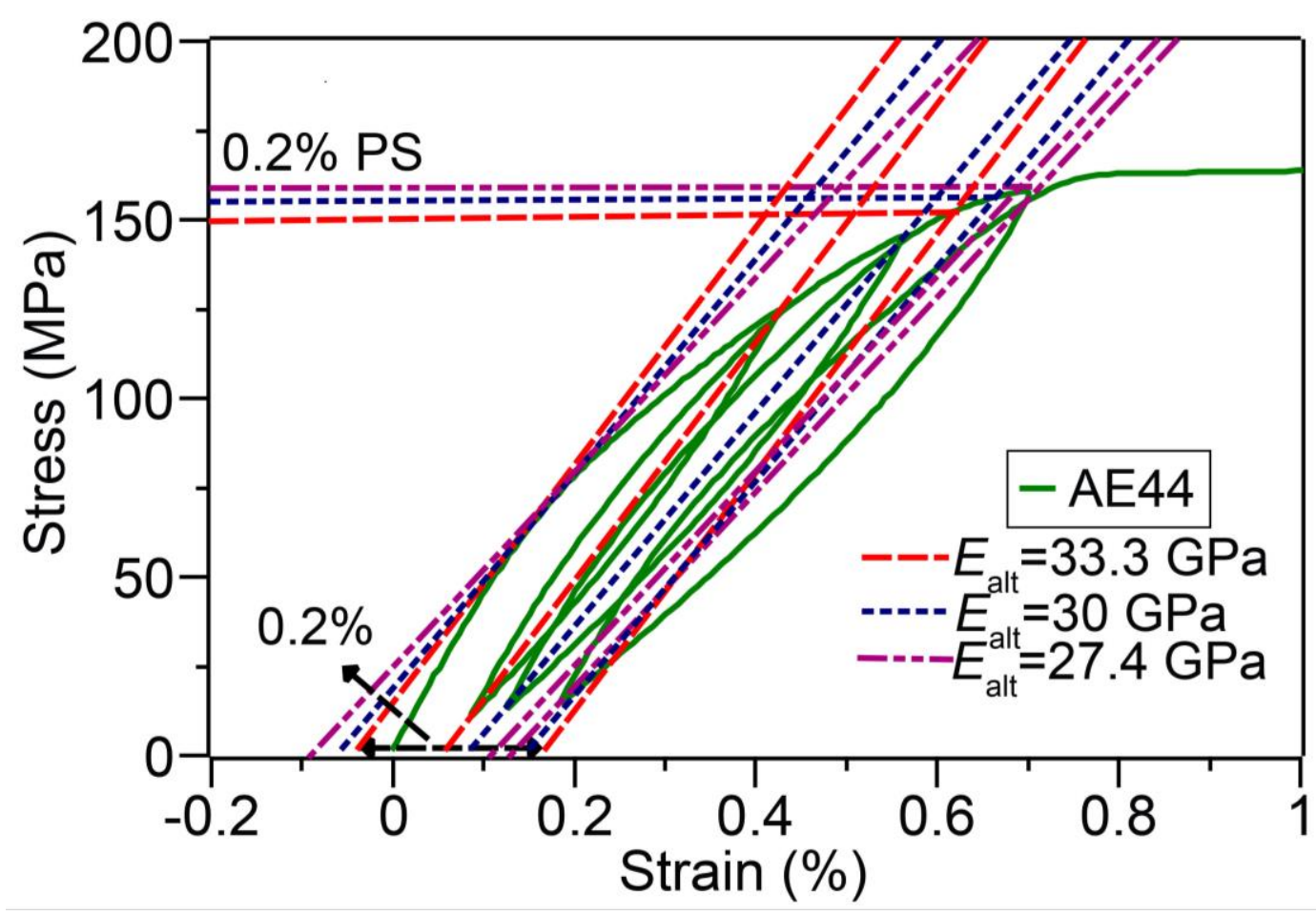

Fig. 8. Inconsistency within Method 4 providing different alternative elastic moduli, $E_{\text {alt }}$, leading to a variation in proof stress values. 

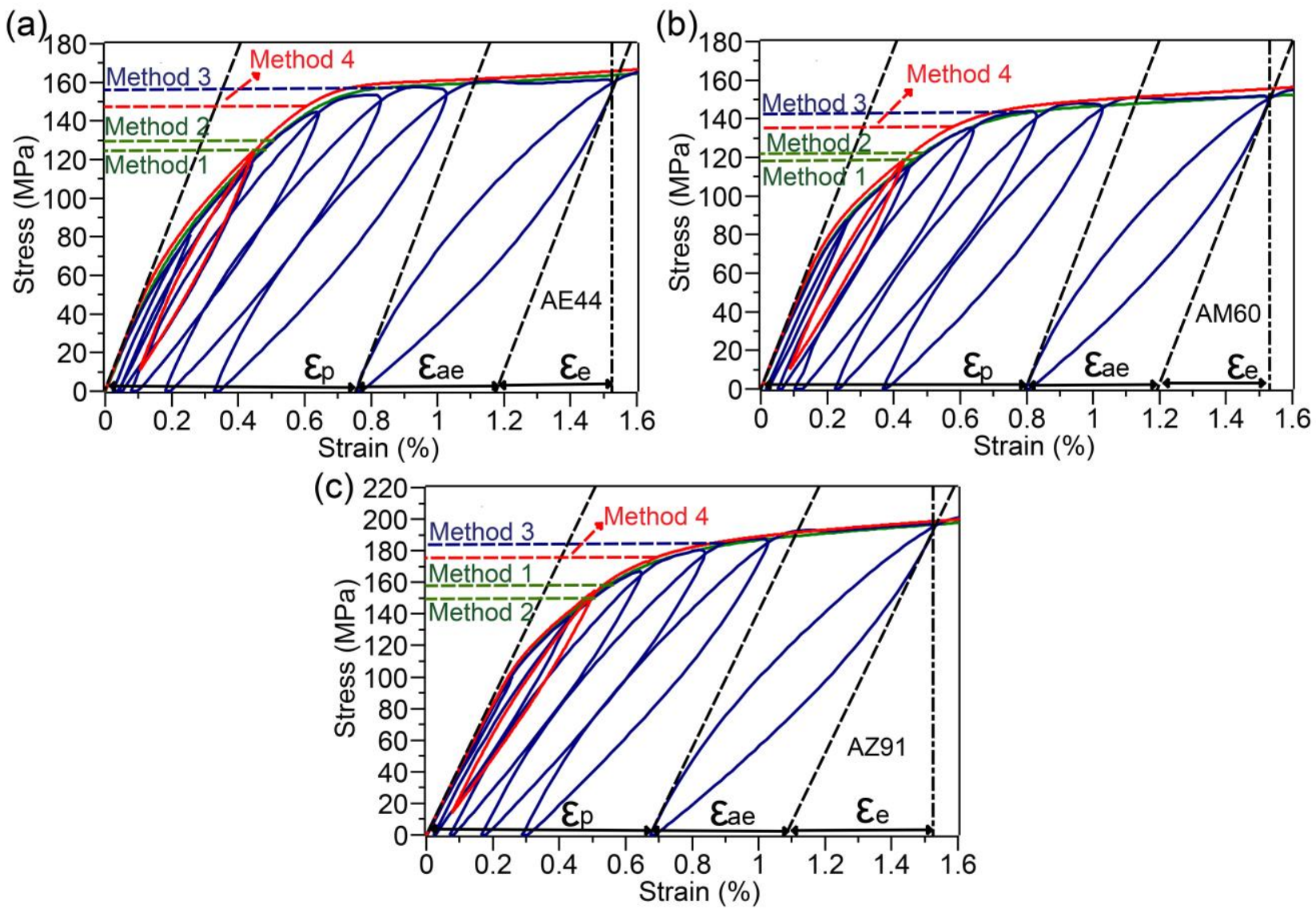

Fig. 9. An overview of monotonic and cyclic stress-strain curves of die-cast (a) AE44, (b) AM60 and (c) AZ91 where the total strain $\left(\varepsilon_{\mathrm{t}}\right)$ can be separated into plastic strain $\left(\varepsilon_{\mathrm{p}}\right)$, anelastic strain $\left(\varepsilon_{\mathrm{ae}}\right)$ and elastic strain $\left(\varepsilon_{\mathrm{e}}\right)$. Proof stress values measured by Methods 1-4 are also shown. 


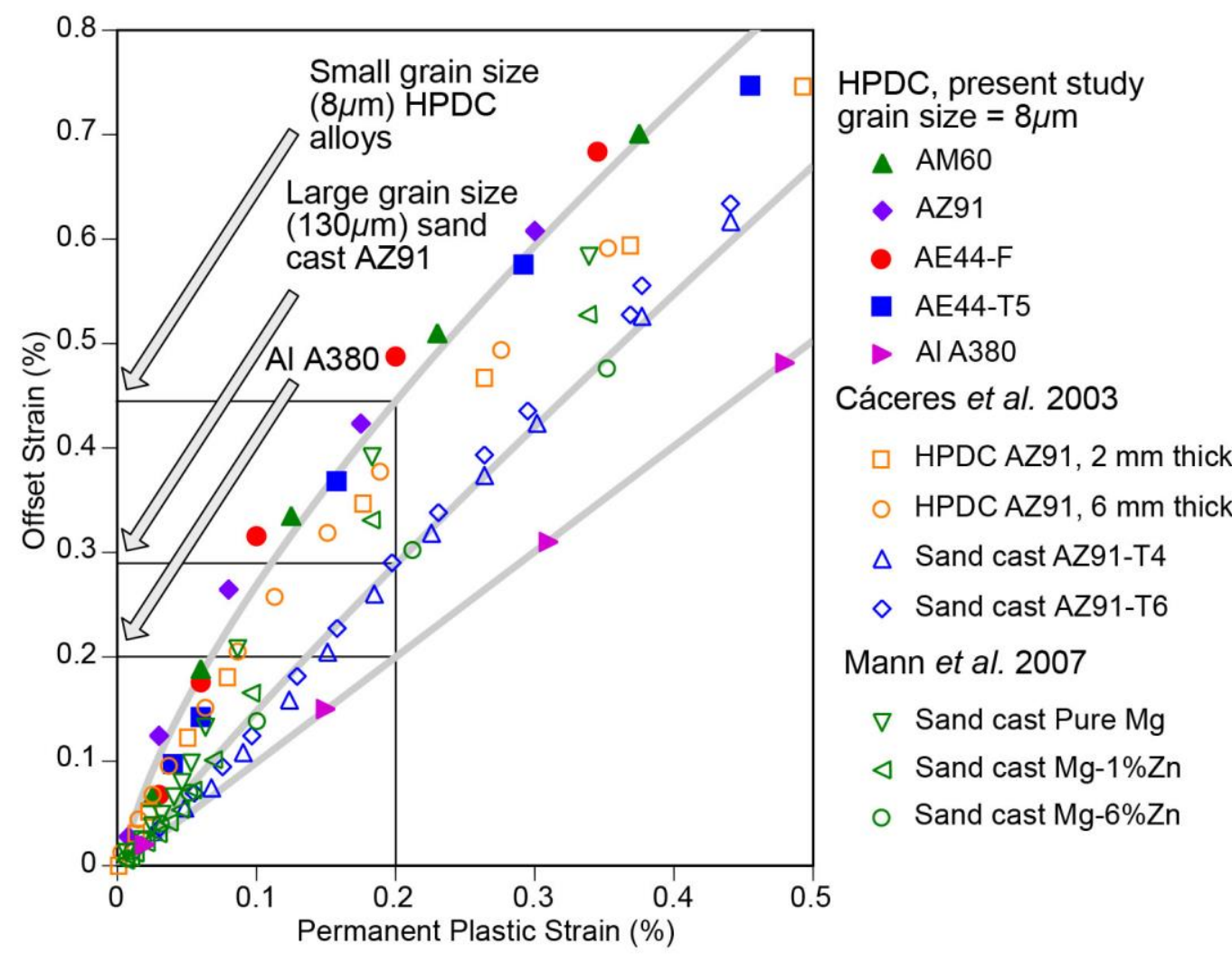

Fig. 10. Permanent plastic strain as a function of offset strain (plastic strain + anelastic strain) for die-cast magnesium alloys. Sand cast magnesium alloys taken from literature works [8, 9] are included for comparison. 


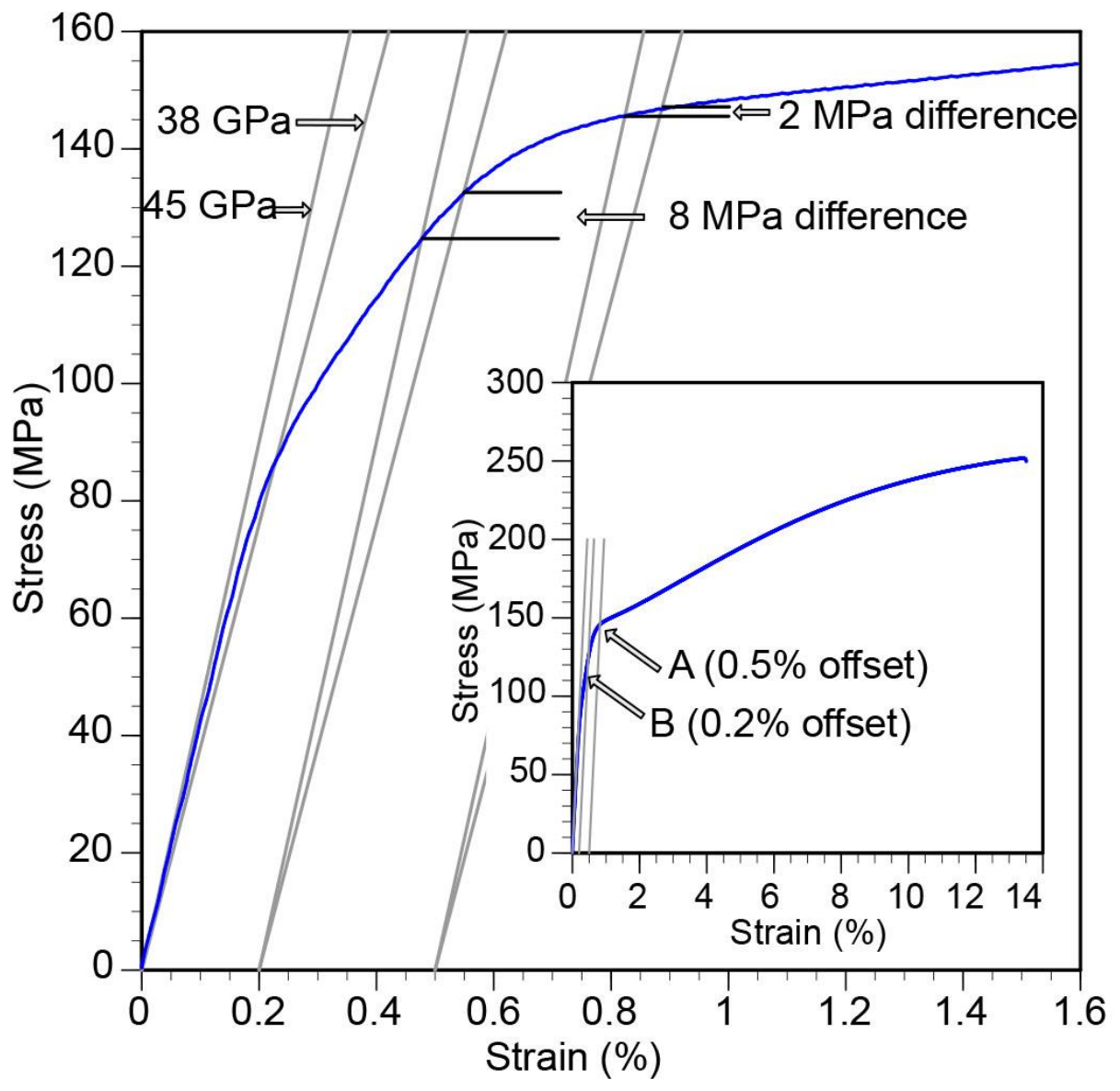

Fig. 11. Stress-strain curve of AM60 showing a comparison of $0.2 \%$ and $0.5 \%$ offsets and the influence of errors in modulus determination. 